\title{
Oscillation Characteristics of Spin-Torque Oscillator Put in Write Gap of SPT Head
}

\author{
T. Takahashi, S. Asaka, K. Yoshida, and Y. Kanai* \\ Kogakuin University, 1-24-2 Nishishinjuku, Shinjuku-ku, Tokyo 163-8677, Japan \\ *Niigata Institute of Technology, 1719 Kashiwazakishi, Fujihashi, Niigata 945-1195, Japan
}

\begin{abstract}
Microwave-assisted magnetic recording (MAMR) has been proposed as a promising technique to achieve a higher areal recording density over $1.0 \mathrm{Tbit} / \mathrm{inch}^{2}$. MAMR requires a spin-torque oscillator (STO) to generate a strong, high-frequency magnetic field to induce magnetic resonance in a recording medium. The oscillation properties of STOs were previously investigated using micromagnetic models. However, simple models were used that neglected the magnetic interactions between the STO and a single-pole-type (SPT) recording head. The interactions and the magnetic field in the gap between the main pole and the trailing shield might strongly affect the oscillating characteristics. Thus, a new simulator that combines an SPT head and an STO simulator, called an integrated MAMR simulator, has been developed. The magnetic interactions between an SPT and an STO are revealed to have considerable effects on the oscillating frequency and the field strength.
\end{abstract}

Key words: microwave-assisted magnetic recording, spin-torque oscillator, micromagnetic simulation, magnetic interaction

\section{ライトギャップ内に配置した STO 素子の発振特性シミュレーション}

\author{
高橋 達明・朝香 壮太・吉田 和悦・金井 靖* \\ 工学院大学，東京都新宿区西新宿 1-24-2（广163-8677） \\ *新潟工科大学, 新潟県柏崎市藤橋 1719（テ945-1195）
}

\section{1. はじめに}

現在，磁気記録では 1Tbits/inch ${ }^{2}$ 超の高記録密度を目指し開発が 盛んに行われている，高記録密度化を実現するためにはトリレン マを解決する必要がある. トリレンマとは「媒体磁化の熱摇らぎ, 垂直磁気異方性磁界，ヘッド磁界」の 3 つのトレードオフ関係の ことである. その解決法の 1 つとして, 高周波磁界による磁気共 鳴を用いたマイクロ波アシスト磁気記録 (Microwave-assisted

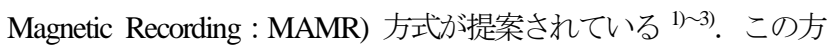
式では，磁気ヘッドから発生する記録磁界に直交する面に GHz 才 一ダーの高周波磁界を重畳し, 記録媒体に磁気共鳴を起こさせる. これによってマイクロ波のエネルギーが媒体を構成する磁性粒子 に吸収されるため, スイッチング磁界に達しなくても媒体での記 録が可能となる.これにより大きな磁気異方性をもつ材料を記録 媒体に用いることが可能となり，トリレンマ問題を解決すること が可能となる.この方式では $10 \mathrm{GHz}$ 以上の高周波磁界で発振する 素子(Spin Torque Oscillator : STO)が必要である.

STO に関しては多くの報告はあるが，それらは主にシミュレー ションによるものであり，空間的に孤立した条件で検討したもの

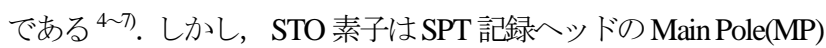
と Trailing Shield(TS)間に配置する. したがって，MP と TS 間のギ ヤップ磁界を実際に取り入れて STO の発振特性を計算する必要が ある. また，このとき SPTヘッドと STO間の磁気的相互作用を取 り入れる必要がある。 そこで，我々は当研究室で開発した磁気記 録シミュレーター ${ }^{8)}$ (SPTヘッドシミュレーター) と孤立 STO 素 子シミュレーターの統合を試みた ${ }^{4) 77}$. 以後, このシミュレーター を統合シミュレーター(integrated simulator)と呼ぶことにする．本報
告では統合シミュレーターの概要とそれを用いてSTO の発振特性 の計算を試みた結果を報告する。ここで孤立 STO 素子シミュレー ター(isolated STO simulator)とは実際のギャップ磁界や相互作用を 考慮していない空間的に孤立したSTOの発振特性を計算する従来 のシミュレーターを意味する.

\section{2. 計算モデル及び計算条件}

Fig.1 に統合計算モデルを示す. Fig.1 に示したようにSPTヘッド の Main Pole と Trailing Shield の間に STO 素子を配置した. Fig.1の

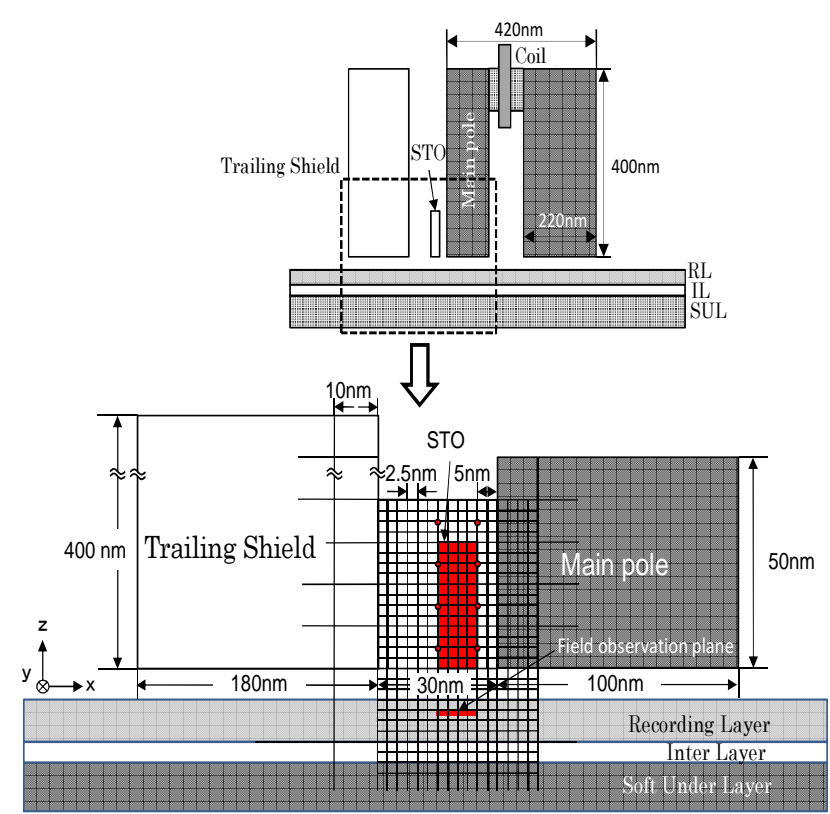

Fig. 1 Calculation model of integrated simulator. 
下図に示したように通常 SPTヘッドは 5～10 nm のセルで空間を 離散化しているのに対して，STO 素子では安定した解を得るには セルを $3 \mathrm{~nm}$ 以下にする必要がある. 今回の計算ではセルサイズを SPTヘッド領域は $10 \mathrm{~nm}, \mathrm{STO}$ 素子領域を $2.5 \mathrm{~nm}$ に設定した. STO 素子の磁化挙動の計算には次式に示したスピントルク項を含めた Landau-Lifshitz-Gilbert(LLG)方程式を用いた.

$$
\begin{gathered}
\left(1+\alpha^{2}\right) \frac{d M}{d t}=-\gamma \vec{M} \times\left(\vec{H}_{e f f}-\alpha \vec{H}_{s t}\right)-\frac{\lambda}{M_{s}} \vec{M} \times \vec{M} \times\left(\alpha \vec{H}_{e f f}+\vec{H}_{s t}\right),(1) \\
\vec{H}_{s t}=a_{j} \vec{M}_{p}=\frac{\hbar \eta J}{2 e M_{s} d} \vec{M}_{p .}
\end{gathered}
$$

式(1)の $\vec{H}_{s t}$ は偏極したスピンによる磁界を表すべクトルである. スピントルク磁界 $\vec{H}_{s t}$ の方向はリファレンス層の磁化方向 $\left(\vec{M}_{P}\right.$; 単 位ベクトル)と等しく，その大きさは aj で表される. J は注入電流 密度, $\mathrm{d}$ はSTO 素子の膜厚, $\eta$ はスピン分極率である.

SPTヘッドと STO 素子間の静磁気的相互作用は次のように計算 した. LLG 方程式を解く時に STO 素子の有効磁界に SPT ヘッド から生じる磁界を加え, 一方 SPT ヘッドの有効磁界を計算する時 にSTO から生じる磁界を加えた. しかしこの時, SPT 領域と STO 領域にはセルサイズの不一致が生じる. そのため四角柱における 内挿計算法を用いることによってこの問題に対処した. 同様に記 録媒体と STO の相互作用についても, STO の空間部において計算 領域を媒体部にまで拡大寸ることによって，上記した方法で計算 することができる. このような方法でプログラムの大幅な変更を 必要とせずに，全ての相互作用を含めたプログラムを作成するこ とができる.ただし，今回は本来計算を行わなければならない媒 体と STO との相互作用は考慮しておらず, SPTヘッドと STO 間の 相互作用のみに着目している. また，STO のリファレンス層は計 算を簡単化するために省略した.

次にそれぞれの計算条件を示す. SPT ヘッドの飽和磁化 Ms を $2.5 \mathrm{~T}$, 磁気異方性定数 $\mathrm{K}$ を $3.0 \times 10^{3} \mathrm{~J} / \mathrm{m}^{3}$, 交換定数 A $2.0 \times 10^{-11}$ $\mathrm{J} / \mathrm{m}$ ，ダンピング定数 $\alpha$ を 0.1 , 励磁電流 $\mathrm{Ij}$ は $-0.18 \mathrm{~A}$, 時間刻多幅 $\triangle \mathrm{T}$ は $0.2 \mathrm{ps}, \mathrm{SPT}$ ヘッドと媒体間のスペーシング $7.5 \mathrm{~nm}$ と設定し た. 媒体は記録層(Recording Layer : RL), 中間層(Inter Layer : IL), 軟 磁性下地層(Soft Under Layer : SUL)から構成されている. SPTへッ ドと Trailing Shield(TS)及び媒体のサイズは Table 1 に示した通りで

Table 1 Geometric sizes of main pole and

\begin{tabular}{|c|c|c|c|}
\hline \multicolumn{3}{|r|}{ Items } & Dimensions \\
\hline \multirow{6}{*}{ 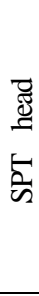 } & \multirow{3}{*}{$\stackrel{p}{z}$} & Thickness [nm] & 100 \\
\hline & & Track width [nm] & 70 \\
\hline & & Throat height [nm] & 50 \\
\hline & \multirow{3}{*}{ 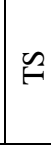 } & Thickness [nm] & 180 \\
\hline & & Width [nm] & 540 \\
\hline & & Height [nm] & 400 \\
\hline \multirow{3}{*}{\multicolumn{2}{|c|}{2}} & RL thickness [nm] & 13 \\
\hline & & SUL thickness [nm] & 60 \\
\hline & & IL thickness [nm] & 5 \\
\hline
\end{tabular}
recording medium.

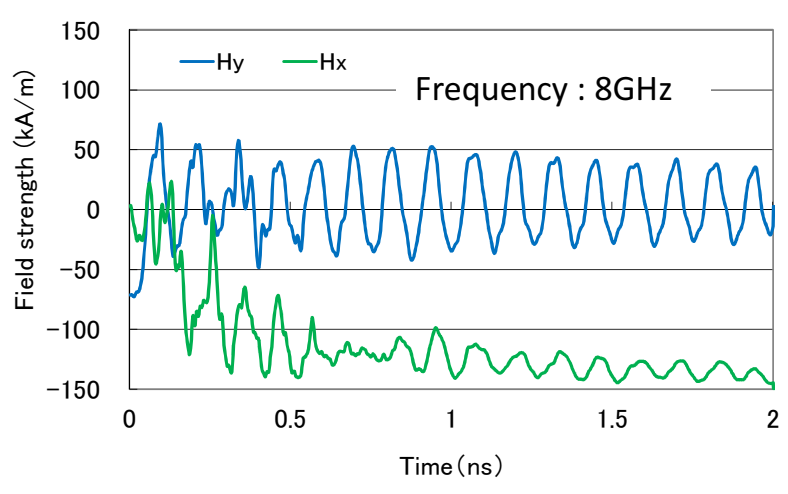

Fig. 2 Oscillating fields calculated with integrated simulator. $\mathrm{K}=5.0 \times 10^{5} \mathrm{~J} / \mathrm{m}^{3}, \mathrm{H}_{\mathrm{st}}=2.0 \times 10^{4} \mathrm{~A} / \mathrm{m}$.

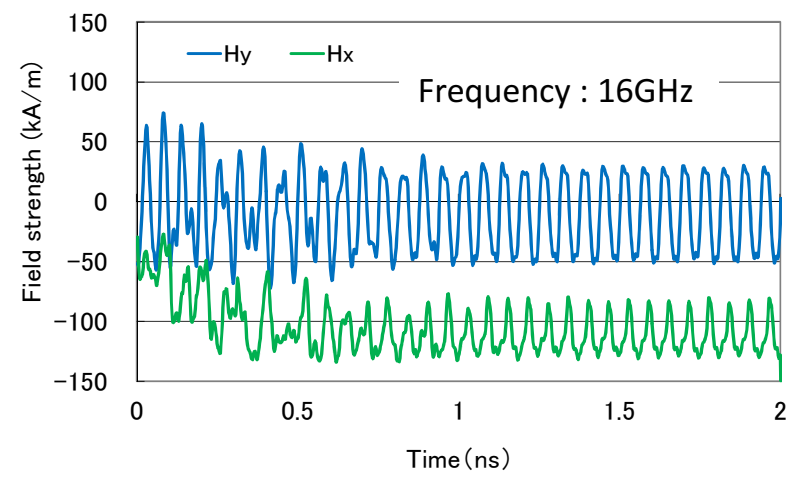

Fig. 3 Oscillating fields calculated with isolated STO simulator.

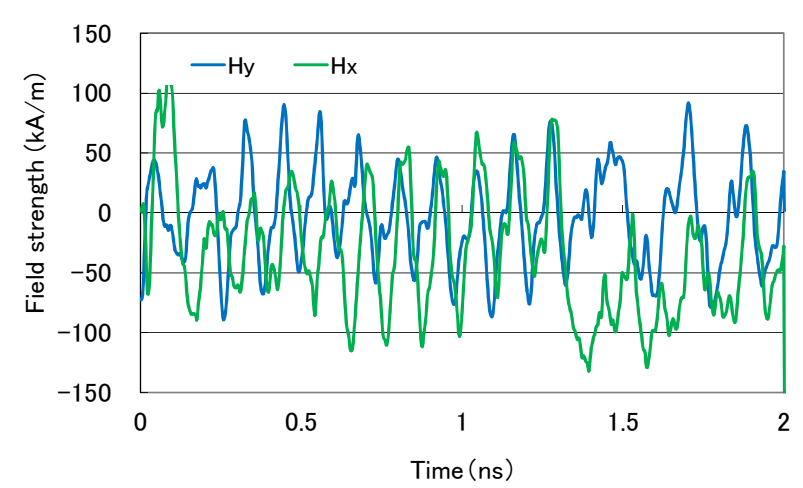

(a) Without interaction

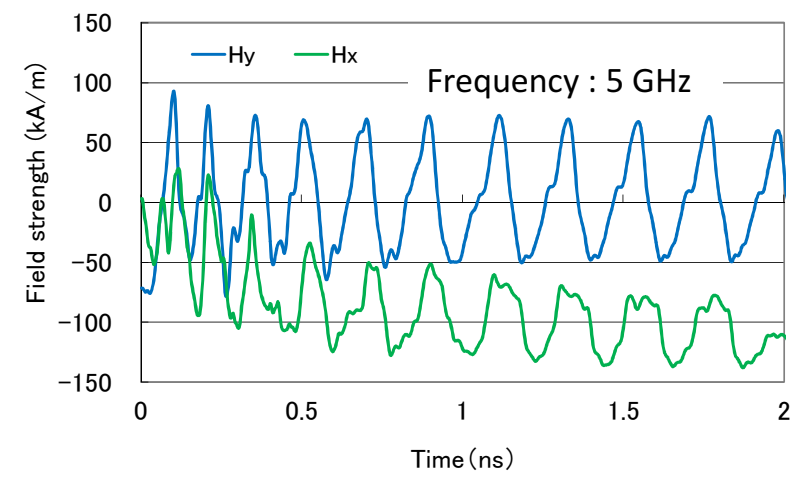

(b) With interaction

Fig. 4 Effects of interactions between SPT head and STO on oscillating properties.

$\mathrm{K}=3.0 \times 10^{5} \mathrm{~J} / \mathrm{m}^{3}, \mathrm{Hst}=-2.0 \times 10^{4} \mathrm{~A} / \mathrm{m}$. 
ある.なお磁化容易軸は記録層で面垂直方向 $(\mathrm{z}$ 軸)にした以外は, SPT と SULはともにクロストラック方向(y 軸)に向けた.

一方 STOの計算条件は, STOサイズは $30 \times 30 \times 10 \mathrm{~nm}^{3}$, 飽和磁化 Ms $2.0 \mathrm{~T}$, 磁気異方性定数 $\mathrm{K}$ を $3.0 \times 10^{5}$ または $5.0 \times$ $10^{5} \mathrm{~J} / \mathrm{m}^{3}$, 交換定数 $\mathrm{A}$ を $2.0 \times 10^{-11} \mathrm{~J} / \mathrm{m}$ ，ダンピング定数 $\alpha$ を 0.02 とした. 本来 SPTヘッドにおいてもダンピング定数を 0.02 として 計算を行う必要があるが，計算時間の関係上異なる值を使用した が，今後は 0.02 を使用して計算を行う。磁化容易軸を STO 膜面垂 直方向に配向させた. スピントルク磁界 Hst を-2.0× $10^{4} \sim-6.0 \times$ $10^{4} \mathrm{~A} / \mathrm{m}$ ( $\mathrm{J}$ 換算: $2.4 \times 10^{12} \sim 7.3 \times 10^{12} \mathrm{~A} / \mathrm{m}^{2}$ ), 時間刻み幅 $\angle \mathrm{T}$ を 0.02 $\mathrm{ps}$ ，スピン分極率 $\eta$ を 0.5 とした. 初期磁化方向は SPT ヘッドと STO 素子ともにy 軸方向とした.

\section{3. 計算結果}

\section{1 統合シミュレーターにおける唚振特性}

Fig.2 に SPT ヘッドと STO 素子の相互作用を考慮した，すな わち統合シミュレーターで計算した場合の発振磁界の経時変化を 示す.このとき TSサイズは $\mathrm{x}$ 方向(down-track)に $180 \mathrm{~nm}, \mathrm{y}$ 方 向(cross-track)に $540 \mathrm{~nm}, \mathrm{z}$ 方向に $400 \mathrm{~nm}$ とした. 縦軸は STO 直下 $9 \mathrm{~nm}$ にある観測面 $\left(30 \times 10 \mathrm{~nm}^{2}\right)$ における平均磁界強度を表 している. STO の計算条件は $\mathrm{K}=5.0 \times 10^{5} \mathrm{~J} / \mathrm{m}^{3}, \mathrm{Hst}=-2.0 \times 10^{4}$ $\mathrm{A} / \mathrm{m}\left(\mathrm{J}=2.4 \times 10^{12} \mathrm{~A} / \mathrm{m}^{2}\right)$ である. Fig.2 は磁界の $\mathrm{x}$ 成分と $\mathrm{y}$ 成分の みを示している. これはへッドの磁界に対して, 直交する成分 $(\mathrm{x}$, $\mathrm{y}$ 成分) のみが媒体の磁気共鳴に寄与するためである. $0 \sim 1 \mathrm{~ns}$ の 間では発振は不安定であるが，これは y 軸方向に向けた初期磁化 が安定発振状態になるまでの過程であり, 1ns 以降で安定した発振 が得られる. なお, 1ns 以降では Main poleから発生する磁界は飽 和状態となっている. 安定発振領域では発振周波数は $8 \mathrm{GHz}$, 高周 波磁界振幅值は $30 \mathrm{kA} / \mathrm{m}$ となる. そこで, この結果を従来の孤立 $\mathrm{STO}$ 素子シミュレーターで計算した結果との比較を行う.

\section{2 孤立 STO 素子シミュレーターとの比較}

Fig.3 に孤立 STO 素子シミュレーターの計算結果を示寸.この 時, 外部磁界として加えた磁界は統合シミュレーターで計算時に 相互作用を考慮した計算において，STO に印加される磁界(後に Fig.6 に示す)である. Fig.2 と比較すると, 発振周波数は統合シ ミュレーターでは $8 \mathrm{GHz}$ であったのに対し, 孤立STO素子シミ ュレーターでは $16 \mathrm{GHz}$ である. 統合することで発振周波数は 2 分の 1 に低下したことが確認できる. さらに, 磁界強度を比較す ると統合シミュレーターでは平均磁界強度が $30 \mathrm{kA} / \mathrm{m}$ であったの に対し, 孤立 $\mathrm{STO}$ 素子シミュレーターでは $40 \mathrm{kA} / \mathrm{m}$ となった. このように両者において計算結果は異なっており, 統合シミュレ ーターでは発振周波数, 磁界強度は伴に減少寸る結果となった. 次にその原因について考察する.

\section{4. 考察}

上記した結果となった原因としては次の 2 点が考えられる.

(1) メインポールとSTOの相互作用.

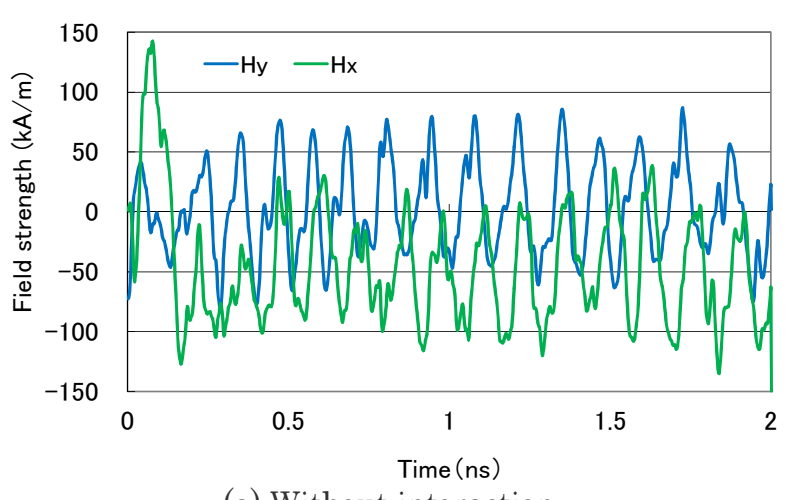

(a) Without interaction

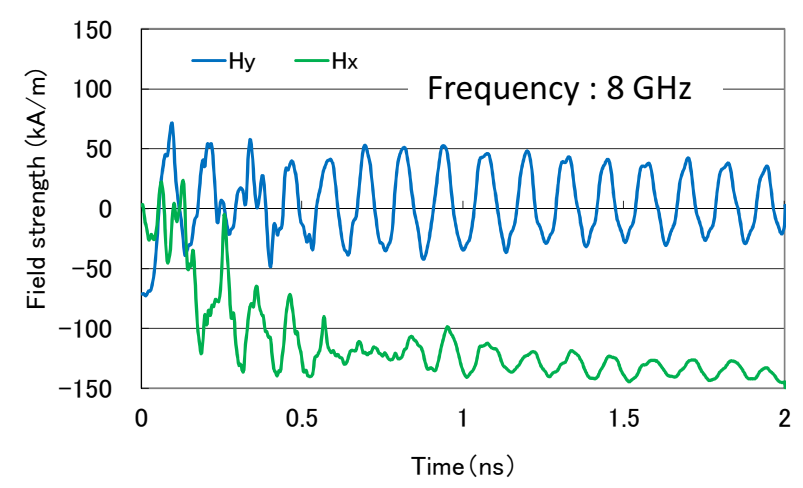

(b) With interaction

Fig. 5 Effects of interactions between SPT head and STO on oscillating properties.

$\mathrm{K}=5.0 \times 10^{5} \mathrm{~J} / \mathrm{m}^{3}, \mathrm{Hst}=-2.0 \times 10^{4} \mathrm{~A} / \mathrm{m}$.

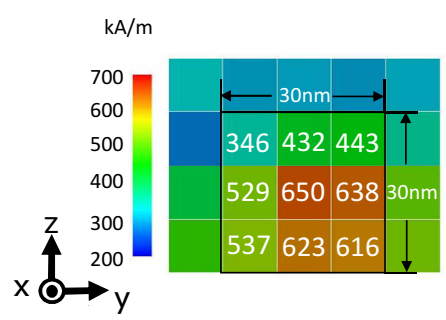

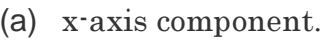

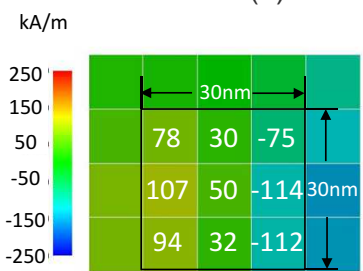

(b) y-axis component.

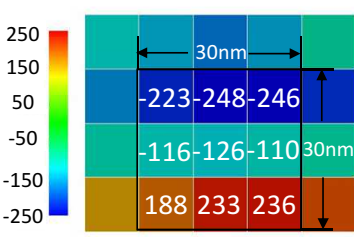

(c) z-axis component.
Fig. 6 Gap field distributions in STO plane with interaction. $\mathrm{K}=5.0 \times 10^{5} \mathrm{~J} / \mathrm{m}^{3}, \mathrm{H}_{\mathrm{st}}=-2.0 \times 10^{4} \mathrm{~A} / \mathrm{m}$.

(2) ギャップ磁界の不均一性.

まず, 1 番目のメインポールとの相互作用が発振特性に与える影 響を検討した. この検討を行うために，STO の LLG 計算におい て, ギャップ磁界を有効磁界に加えるが, SPT の有効磁界計算時 にはSTO からの磁界を加えずに計算を行った.これによって SPT 
ヘッドとSTOの磁気的相互作用を断つことができる. 結果をFig.4, Fig.5 に示寸. Fig.4 は異方性定数 K の值を $3.0 \times 10^{5} \mathrm{~J} / \mathrm{m}^{3}$ にした 場合であり, Fig. 5 は K を $5.0 \times 10^{5} \mathrm{~J} / \mathrm{m}^{3}$ にした場合である. 両図 とも(a)は相互作用を考慮していない場合，(b)は相互作用を考慮し た場合である、いずれの場合でも(a)，(b)を比較すると，今回の計 算条件においては相互作用を考慮した方が発振は安定しているこ とが分かる. 一方, 発振磁界強度は相互作用により減少している.

このように, SPT ヘッドと STO 間の磁気的相互作用は発振特性 に大きな影響を与えることが分かった.

このような違いが生じる原因として, 相互作用の有無によって ギャップ磁界の強度や分布が変わることが考えられる. そこで, STO に掛かるギャップ磁界の分布を調べた. Fig.6 に STO 膜面内 における磁界分布を示す. 図中にSTO 領域を黒枠で囲った. Fig.6 の(a)はギャップ磁界の $\mathrm{x}$ 成分であり，(b)は $\mathrm{y}$ 成分，(c)は $\mathrm{z}$ 成分の 磁界強度分布である. この結果はFig. 2 に示した発振磁界におい て 1.5ns 時におけるギャップ内磁界分布に相当している. Fig.6 (a) を見ると STO 素子に掛かるギャップ磁界はSTO の中心位置で最 大 $650 \mathrm{kA} / \mathrm{m}$ となっているが, 左上の位置で $346 \mathrm{kA} / \mathrm{m}$ とかなり 減少することが分かる. Fig.6 (b)，(c)を見ると x 成分ほど磁界は強 くはないがやはり不均一に分布していることが分かる.

次に相互作用を考慮していないときのギャップ磁界分布を Fig. 7 に示寸.これは Fig. 5(a)に示した相互作用を考慮しなかった発振 磁界において $1.5 \mathrm{~ns}$ 時におけるギャップ内磁界分布に相当してい る. 相互作用を考慮した Fig.6 (a) と比較すると x 成分は約 30\%減 少している. この差は相互作用の有無によってもたらされたもの であり, 相互作用により STOにかかるギャップ磁界は増加するこ とが分かる.

以上示したようにギャップ磁界は相互作用の有無にかかわらず 極めて不均一であり、かわその強度は相互作用に影響されること が分かった. このギャップ内の磁界そのものが発振特性に与える 影響を検討寸るには, 相互作用を含まない孤立STO 素子シミュレ ーターに上記したギャップ磁界を導入し, その発振特性を統合シ ミュレーターで得られた結果と比較することが有効である.もし その結果が両者で一致するならば, Fig.4 と Fig.5に示した相互作 用の有無による発振特性の違いは,ギャップ内磁界分布の違いが原 因であると結論できる. もし再現できない様であれば，その原因 は相互作用にあることが明瞭となる. この考えに従って計算した 結果が Fig. 3 である. Fig. 6 に示した極めて不均一な分布をもつ 磁界を, 孤立 STO 素子シミュレーターのSTOに印加しても安定 して発振しており, 周波数も $16 \mathrm{GHz}$ と高く, Fig. 2 に示した統合 シミュレーターの計算結果を再現することはできない. この結果 は, ギャップ内に配置された STO の発振特性は, 磁界分布の非一 様性よりも SPTヘッドとの相互作用に大きく影響されることを明 瞭に示寸ものである.

なお、この考えを裏付けるために Fig. 7 に示した相互作用が無 い時の磁界を孤立 STO シミュレーターに導入して計算を行った. その結果を Fig. 8 に示寸. この図と相互作用を断った条件で統合 シミュレーターを使って計算した Fig. 5(a)を比較してみる. 最初 の $1 \mu \mathrm{s}$ までは両者の結果は異なるが, $1 \mu \mathrm{s}$ 以降は発振周波数が約 7

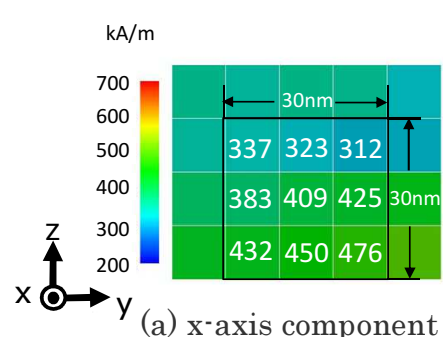

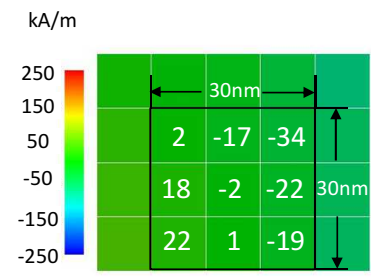

(b) y-axis component.

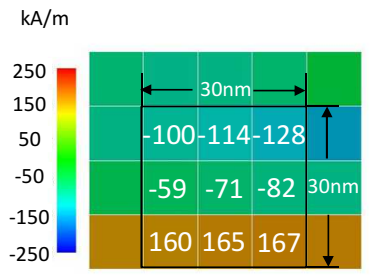

(c) z-axis component.
Fig. 7 Gap field distributions in STO plane without interaction.

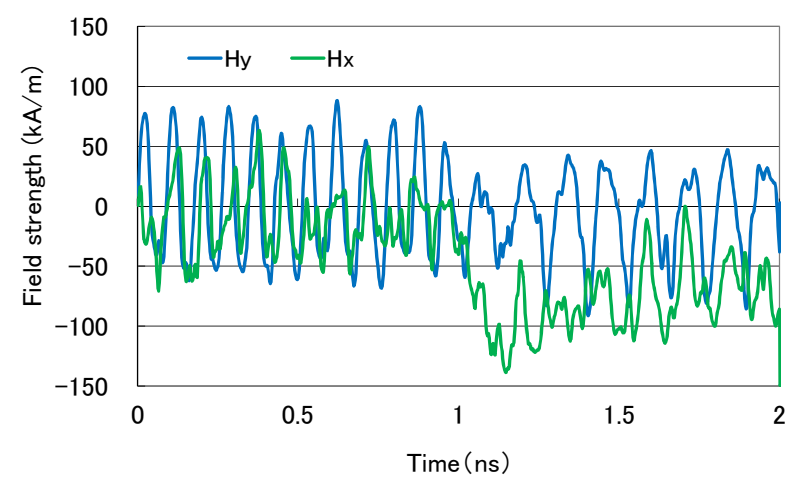

Fig. 8 Oscillating fields calculated with isolated STO simulator. The magnetic fields of Fig. 7 are used. $\mathrm{K}=5.0 \times 10^{5} \mathrm{~J} / \mathrm{m}^{3}, \mathrm{H}_{\mathrm{st}}=-2.0 \times 10^{4} \mathrm{~A} / \mathrm{m} . \mathrm{H}_{\mathrm{apl}}=4.0 \times 10^{5} \mathrm{~A} / \mathrm{m}$

$\mathrm{GHz}$ と比較的よく似た発振特性となる. この結果から, 相互作用 が無い場合は, STO に印加される磁界が同じであれば, 統合シミュ レーターで相互作用を断ち切って計算した結果と, 孤立ST0シミ ユレーターでも同じ結果が得られることが確認できる. なお, Fig. 8 において0から $1 \mu \mathrm{s}$ の間で, Fig. 5 (a) と Fig. 8 の振動状態が異 なるのは, 統合シミュレーターではギャップ磁界が Fig. 7 に示し た分布状態に至る過程であり, 孤立STO シミュレーターでは最初 から Fig. 7 に示した磁界が印加されているためである.

以上示したようにSTO と SPT間の磁気的相互作用がSTO の発 振特性に大きな影響を与えることが明らかとなった. 本研究では この相互作用により, どのようなメカニズムを通して STO の発振 特性が影響を受けるかまでは検討していないが，おおよそ次のよ うなことが考えられる. STOから発振した高周波磁界は, SPT ッドのメインポールの磁化を振動させる. するとメインポールか ら高周波磁界が発生し, 逆にSTO がその高周波磁界を感じ歳差運 動に大きな変化が生じることが推定される. また, メインポール における磁化の振動はメインポールの共鳴ロスを伴い, 発振周波 数の低下を招くものと推定される. 


\section{5. まとめ}

$\mathrm{SPT}$ ヘッドシミュレーターと孤立 STO 素子シミュレー ターを統合したプログラムを開発し，それを用いることに よって以下のことが分かった。

(1) SPT と STOの相互作用を考慮した統合シミュレーター で計算した STO の発振特性は, 孤立 STO 素子シミュ レーターを用いた場合と大きく異なり，発振周波数の 低下と発振磁界の減少をもたらす結果となった。

（2）その主たる原因は SPT のメインポールと STO との磁 気的相互作用にある.

謝辞本研究はストレージ研究推進機構 (Storage Research Consortium : SRC)及び新エネルギー産業技術総 合開発機構 (New Energy and Industrial Technology Development Organization : NEDO)の支援により行いま した.

\section{References}

1) J- G. Zhu, X. Zhu, and Y. Tang, "Microwave Assist Magnetic Recording,” IEEE Trans. Magn., 44, No.1, 125 $-131(2008)$
2) X. Zhu and J-G. Zhu, "Bias-Field-Free Microwave Oscillator Driven by Perpendicularly Polarized Spin Current, " IEEE Trans. Magn., 42, No.10, 2670. 2672(2006).

3) Y Tang, and J.G Zhu, "Narrow Track Confiement by AC Field Generation Layer in Microwave Assisted Magnetic Recording" IEEE Trans. Magn., 44, No. 11, 3376 - 3379 (2008).

4) Houssameddine.D,et al, "Spin-torque oscillator using a perpendicular polarizer and a planar free layer ," Nature Mater. , 16, 447-453(2007).

5) K.Yoshida, M.Yokoe, Y. Ishikawa, and Y. Kanai, "Spin Torque Oscillator With Negative Magnetic Anisotropy Materials for MAMR , " IEEE Trans. Magn., 46, 2466-2469 (2010).

6) K.Yoshida, and E.Uda, N.Udagawa, and Y. Kanai, "Investigation on magnetic Fields From Field-Generating Layer in MAMR ," IEEE Trans. Magn., 44, No. 11, 3408 3411 (2008).

7) E.Uda, M.Yokoe, K.Yoshida, and Y. Kanai, "Oscillation Characteristics and Infuluences of Eddy Current on Oscillator for MAMR ," J. Magn. Soc. Jpn., 33, 357 -361(2009).

8) E.Uda, K.Yoshida, and Y. Kanai, " Micromagnetic Calculations of SPT Head Field with Trailing Shield ," $J$. Magn. Soc. Jpn., 32, $201-204(2008)$.

2011年10月27日受理，2012年3月16日操録 